Article

\title{
Integrated Evaluation of Hybrid Water Supply Systems Using a PROMETHEE-GAIA Approach
}

\author{
Mukta Sapkota ${ }^{1, *(D)}$, Meenakshi Arora ${ }^{1}$, Hector Malano ${ }^{1}$ (D), Ashok Sharma ${ }^{2}$ and \\ Magnus Moglia ${ }^{3}$ \\ 1 Department of Infrastructure Engineering, Melbourne School of Engineering, University of Melbourne, \\ Melbourne, VIC 3010, Australia; marora@unimelb.edu.au (M.A.); h.malano@unimelb.edu.au (H.M.) \\ 2 ISILC (Institute of Sustainable Industries \& Liveable Cities) and College of Engineering and Science, \\ Victoria University, Footscray, VIC 3030, Australia; Ashok.Sharma@vu.edu.au \\ 3 CSIRO Land and Water, Clayton, VIC 3169, Australia; Magnus.Moglia@csiro.au \\ * Correspondence: sapkotam@unimelb.edu.au; Tel.: +61-383-449-841
}

Received: 9 April 2018; Accepted: 7 May 2018; Published: 8 May 2018

\begin{abstract}
There are pressures on existing centralized water infrastructures in urban centers which justify the search for alternatives. An increasingly important alternative is to shift from centralized to hybrid systems, often in response to climate variability and demographic changes. In a hybrid system, water is supplied and discharged through a mix of centralized and decentralized systems. There is usually no single objective that justifies the choice of hybrid water systems, but they typically are justified based on the consideration of a number of different criteria in order to evaluate the overall quality of service provision. The most important criteria include meeting water demand, as well as reducing demand for fresh water and instead using local alternative water supplies. Integration of multiple objectives to evaluate the hybrid water supply systems can be accomplished by multi-criteria decision aid techniques. This paper evaluates a number of hybrid water supply scenarios using a case study based on the Northern Growth Area of Melbourne, Australia. It uses the Preference Ranking Organization METHod for Enrichment Evaluations (PROMETHEE) and Geometrical Analysis for Interactive Decision Aid (GAIA), one of the multi-criteria decision-making methods through D-Sight software, to rank the hybrid water supply scenarios, and this ranking is validated by means of sensitivity analysis. The centralized system combined with stormwater harvesting and the centralized system combined with treated wastewater and rainwater tanks yielded the first and second most preferred scenarios, while the centralized water supply system combined with treated wastewater yielded the worst hybrid water supply option.
\end{abstract}

Keywords: hybrid water supply system; multi-criteria decision analysis; PROMETHEE; GAIA; D-Sight

\section{Introduction}

As the population in cities increase, it changes the water demand patterns. This, when coupled with often periodic drought and climate change has put a significant pressure on traditional water systems in many cities, which are typically based on only a centralized water supply system $[1,2]$. In response to the need to improve water supply resilience, many cities have diversified their systems by using a range of technologies [3]. Thus, many urban water managers around the world have adopted what is referred to as decentralized water supply options, such as wastewater reuse, rainwater tanks, and stormwater harvesting in combination with a centralized system based on dams and pipe networks $[4,5]$. Such combinations of centralized-decentralized systems is referred to as hybrid water systems in this paper [6]. 
Whilst the introduction of new alternative water supply technologies has many benefits, there are also some trade-offs to be made. For example, it has been demonstrated that the use of decentralized water supply options in combination with centralized water, wastewater, and stormwater systems alters both the wastewater and stormwater flow and contaminants' composition [7]. There are also other trade-offs to be made when introducing alternative water supply technologies [8]. For example, when choosing a particular hybrid system, there is a need to take into consideration a number of different criteria/objectives for water service provision alternatives, such as meeting water demand, supplying water reliably, using alternative water supply/discharge options, reducing contaminants concentration of wastewater, and reducing fresh water loads [9,10]. The presence of trade-offs means that it is important to help decision makers through the provision of decision support tools, such as by means of multi-criteria assessment. Until now, there has only been limited literature available on the topic of integrated evaluation of hybrid water supply systems [11-13], although frameworks do exist to support the evaluation of specific designs of hybrid systems [14]. Previous methods, however, do not explore the impact on wastewater and stormwater flows [9]. To address such limitations of previously available frameworks, the authors [9] developed a new, more comprehensive framework for assessing the integrated impact of hybrid water supply systems in terms of their physical impact on changing wastewater and stormwater quality, as shown in Figure 1. This framework is based on theory and therefore requires empirical validation via case study applications. Sapkota, et al. [15] demonstrated the systematic application of a subset of this framework (marked blue in Figure 1) and highlighted that the framework, to provide the greatest use, should be embedded within a multi-objective decision support approach to provide guidance on choosing the best hybrid water supply scenario.

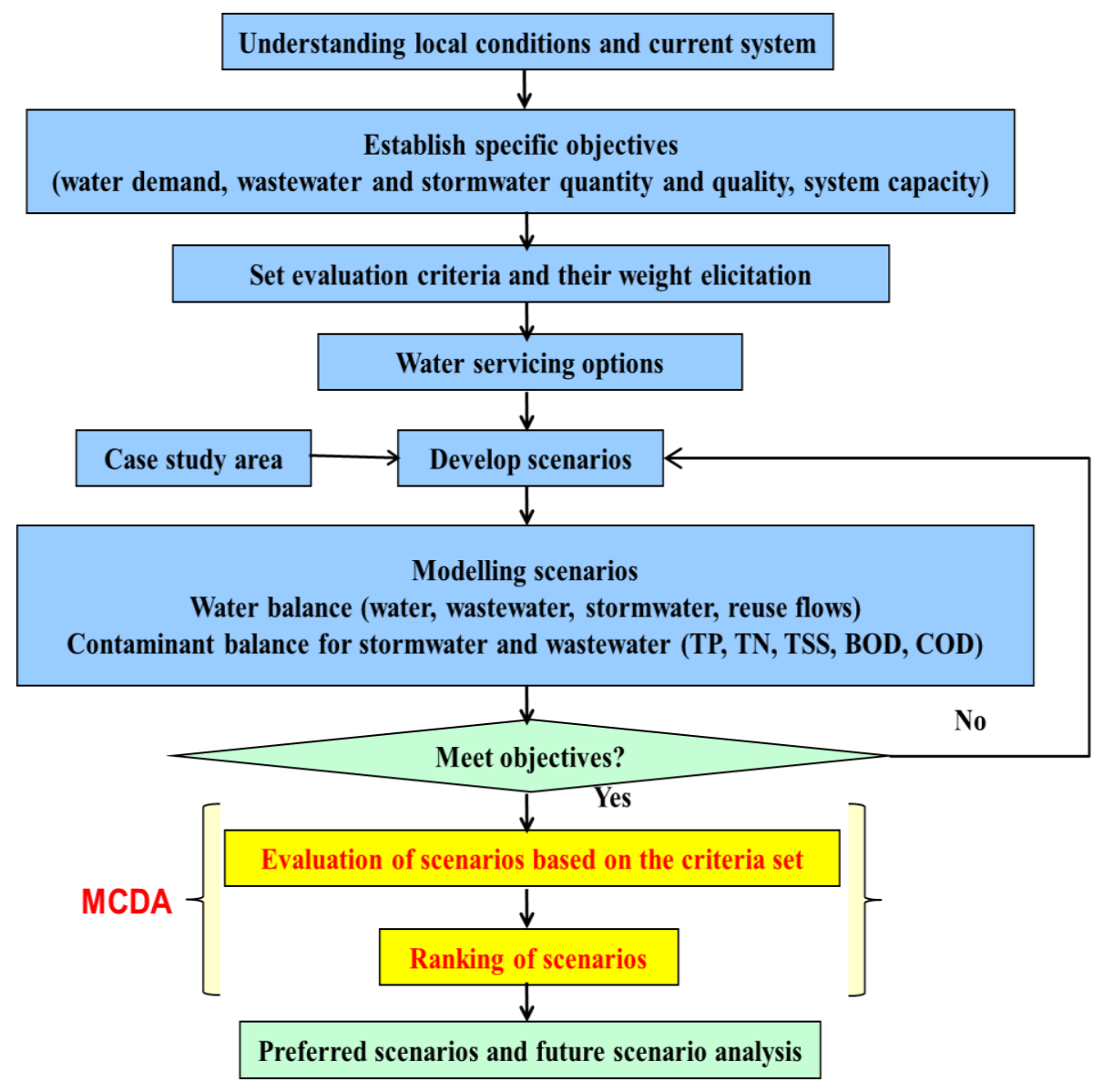

Figure 1. Hybrid water supply system evaluation framework [9]. 
Hybrid water supply systems are typically installed in order to achieve more than one objective [15]. Multi-criteria decision analysis (MCDA) helps decision makers to incorporate preference data on multiple, sometimes conflicting priorities into evaluation and thereby select the best solution from a set of alternatives by assessing performance against a range of criteria $[3,14,16]$. MCDA provides the means to develop future strategies and a systems science methodology to make judgements about trade-offs, ranking servicing options in the presence of objectives and constraints which are sometimes noncommensurable and conflicting [17]. Thus, MCDA has been widely applied in water resources planning [18]. Only some MCDA methods are able to incorporate aleatory and epistemic uncertainty into assessments [19]. This paper evaluates several hybrid water supply scenarios through multi-criteria decision analysis using the Preference Ranking Organization METHod for Enrichment Evaluations (PROMETHEE) outranking method. It uses water and contaminant balance results from [15] as input for the MCDA analysis.

\section{MCDA Methodology}

In the mainstream of MCDA applications, there are some key methods for applying multi-criteria analysis. Traditionally, the main three methods/techniques are the multiple attribute utility theory, interactive technique, and outranking technique [20], explained as follows:

- Multiple attribute utility theory essentially combines multiple objectives into a one-dimensional "multi-attribute" function, which can be a value function that is deterministic or a utility function that includes a measure of risk [21].

- Interactive techniques consist of alternating computation steps and dialogue in the decision making, where the decision maker brings a direct contribution towards the elaboration of a solution by intervening in the process and not just in the definition of the problem [20].

- Outranking methods facilitates pairwise comparisons of alternatives to establish a ranking or partial ranking [22]. The outranking methods are most commonly used, as they are adaptable to real-world problems and are more easily comprehended by decision makers [23].

In some circumstances, it is difficult to choose between different options due to challenging trade-offs [24]. The outranking methods take this into account by allowing a state of incomparability [25]. Moreover, the situation of weak preference is assumed, where one alternative is just slightly better than another one. PROMETHEE is a simple ranking method in conception and application compared with the other methods for multi-criteria analysis [26]. Due to these advantages, PROMETHEE [27], one of the outranking methods, was adopted for use in this study. Furthermore, in this study, PROMETHEE was used along with Geometric Interactive Decision Aid (GAIA) analysis. The GAIA analysis, which is based on principal component analysis, provided a graphical representation of results obtained by the PROMETHEE method and helped in understanding the conflicts among criteria and in dealing with the weights related to them [28,29].

To apply the PROMETHEE method, D-Sight software was selected for ranking the various scenarios based on the results from the water and contaminant balance analysis. D-Sight is the third generation PROMETHEE-based software following PROMCALC and Decision Lab 2000 [30,31]. D-Sight is a collaborative decision-making platform that helps to solve challenges, analyze data, and drive stakeholders together to make a decision [32].

The input data required for D-Sight are:

- Preference Measures (PM) evaluations,

- Weights, and

- Preference functions.

The D-Sight software also incorporates a tool called "Walking Weights" that supports sensitivity analysis $[33,34]$. The sensitivity analysis helps the analyst investigate which, if any, weights have to 
be elicited with a high precision degree and/or if the rankings result significantly changes when the weights are modified [35].

D-Sight supports the GAIA methodology [36]. This enables the graphical investigation of whether there are conflicts between criteria, via principal components analysis, and this provides insights about potential trade-offs to be made by decision makers (DMs) [33,37].

\subsection{PROMETHEE Rankings}

PROMETHEE provides a partial ranking of alternatives based on the positive $(\Phi+)$ and negative $(\Phi-)$ preference flows of the alternatives and highlights any potential incomparability between alternatives. PROMETHEE II provides a complete ranking of alternatives from best to worst based on net preference flow. The PROMETHEE II ranking is prescriptive in nature [37].

\subsection{GAIA Plane}

There is a descriptive complement to the PROMETHEE methodology, the GAIA plane, which is a visual interactive module based on principal component analysis [38]. The GAIA plane provides the decision maker with a synthetic visual representation of the main characteristics of the decision problem [39], such as synergies and conflicts between the preference measures or alternatives [40]. GAIA is referred to as Global Visual Analysis (GVA) in the D-Sight software. Based on these features, PROMETHEE, along with GAIA, is used in this MCDA study.

\subsection{Sensitivity Analysis}

The assessment of decision criteria weights is a crucial step in most of the multi-criteria decision analysis because the choice of weights may considerably influence the global score in the calculation [41]. It is therefore very important to examine the relative impact of possible variations and errors of weightings on outputs by conducting a sensitivity analysis of weights. Further, internal uncertainties in MCDA can be handled by appropriate sensitivity analysis under various circumstances [42].

In D-Sight, this is done by stability intervals. For each PM, a stability interval indicates the range of weights that can be modified without affecting the PROMETHEE II ranking (to a stated "stability level") given that the relative weights of other PMs are kept constant [30]. This feature is very comprehensive and shows how PROMETHEE II ranking varies as a function of the PM weights and identifies the interval stability of top-ranked alternatives [34]. The wider the stability interval for a given PM, the less likely that the corresponding PM weights have an effect on the rankings [43]. Hence, rankings can be considered robust only if the stability intervals are wide for various PMs.

\section{Application of Methodology}

\subsection{Case Study}

The Northern Growth Area (NGA), which includes Wollert, Aurora, Epping North East, and Quarry Hill, was selected as a case study area due to the availability of appropriate data. The NGA has an area of 2257 hectares and is $20 \mathrm{~km}$ north of the city of Melbourne, Australia. The area is currently supplied with Class A water for nonpotable use, including garden watering and toilet flushing. To explore alternatives to centralized water supplies in the NGA, seven scenarios were generated based on consultation with local water utilities as presented below [15]:

I. Scenario 1: Centralized only-It represents the conventional water supply system based exclusively on supplying a treated potable supply using fresh water resources and is used as a reference to compare with the selected hybrid water supply scenarios evaluated in this study.

II. Scenario 2: Centralized along with recycled water via third (separate) pipe-This scenario represents the present condition in the area. In this scenario, wastewater is collected at the 
development level and distributed through a dual reticulation system for toilet flushing and garden irrigation after treatment. The remaining water demand is met from the potable water supply.

III. Scenario 3: Centralized supply combined with treated greywater-In this scenario, greywater is collected from bathroom and laundry use and used for garden irrigation and toilet flushing. Other demands are met via potable supply.

IV. Scenario 4: Centralized supply combined with rainwater harvesting-In this scenario, rain water is provided for the toilet, garden irrigation, and laundry use. Potable water is supplied for bathroom and kitchen use.

V. Scenario 5: Centralized supply combined with stormwater harvesting-In this scenario, stormwater is provided for toilet and garden irrigation. Potable water is supplied for bathroom, laundry, and kitchen use.

VI. Scenario 6: Centralized supply combined with stormwater harvesting and treated grey water-In this scenario, both stormwater and greywater are provided for garden irrigation and toilet use. However, priority is given to greywater over stormwater as greywater occurs at the unit-block scale compared to stormwater, which occurs at precinct scale. Potable water is supplied for bathroom, laundry, and kitchen use.

VII. Scenario 7: Centralized supply combined with rainwater harvesting and recycled water via 3rd pipe - In this scenario, rainwater is provided for laundry use, garden irrigation, and toilet use, while recycled water is also used for garden irrigation and toilet use, and potable water is supplied for bathroom and kitchen use.

\subsection{Evaluation Criteria}

To evaluate the hybrid water supply systems (WSS), various preference measures (criteria) were chosen in consultation with Victorian water utilities through a series of workshops and personal interviews [9]. These included the:

- Reduction in potable water demand from centralized WSS,

- Reduction of wastewater generation,

- Reduction of contaminant (Total Suspended Solids (TSS), Total Phosphorous (TP), Total Nitrogen (TN), Biochemical Oxygen Demand (BOD), and Chemical Oxygen Demand (COD)) concentration in wastewater,

- Reduction in stormwater flow,

- Reduction in contaminant (TSS, TP, TN, BOD, and COD) load in stormwater,

- Increased supply reliability of fit-for-purpose water. Supply reliability is defined as the percentage of average demand met from the combination of alternative water supply storages over the modeling period.

The data for the case study service provision were obtained by water and contaminant balance analysis using Urban Volume and Quality Model (UVQ) [44]. UVQ simulates the integrated water system within an urban area and estimates the water and contaminant flow through existing and/or alternative water, wastewater, and stormwater systems from source to discharge point [45].

\subsection{Data Input}

Three basic data inputs were required for parameterizing the models and ranking the hybrid water supply scenarios using MCDA:

I. Evaluation matrix: This matrix includes $m$ number of alternatives, $\mathrm{n}$ number of PMs, and $(\mathrm{m} \times \mathrm{n})$ number of PM evaluations. Table 1 shows the evaluation matrix formulated. This table is based on the water and contaminant balance analysis output reported in Sapkota, Arora, Malano, Moglia, Sharma and Pamminger [15]. 
II. Weights of PMs: Weights required were evaluated by conducting a questionnaire survey among 37 water professionals which included personnel from water utilities, private water consultancies, CSIRO, universities, environmental agencies, and the Australian Water Association. [46]. Table 2 below presents the weight distribution between different subcriteria for various criteria. For internal consistency reliability of the calculated weights of different subcriteria, Cronbach's alpha [47] was calculated and found to be within the acceptable range of 0.5-0.9 [46]. Further, a weight sensitivity analysis was conducted in MCDA, as suggested by the study.

III. Preference functions of PMs: Preference functions were determined by conducting a questionnaire survey among experts, representing water professionals from Victorian water utilities to determine the preference function [46]. Usual preference function as shown in Figure 2 was used for this study. For this type of function, the decision maker has a strict preference for the alternative having the greatest value [48]. This means that even if there is a very small difference in criterion value, an alternative with a higher value is selected.

Table 1. Input Evaluation Matrix for PROMETHEE.

\begin{tabular}{ccccccccc}
\hline Criteria & Sub Criteria & Sce 1 & Sce 2 & Sce 3 & Sce 4 & Sce 5 & Sce 6 & Sce 7 \\
\hline \multirow{2}{*}{ Potable water supply } & Volume(ML/year) & 1036 & 860 & 859 & 787 & 856 & 856 & 761 \\
& Peak(ML/day) & 6.11 & 5.05 & 5.18 & 6.11 & 4.94 & 4.94 & 5.05 \\
\hline \multirow{2}{*}{ Sewage flow } & Volume(ML/year) & 678 & 511 & 526 & 674 & 678 & 526 & 630 \\
& Peak(ML/day) & 31.7 & 31.5 & 31.5 & 31.7 & 31.7 & 31.5 & 31.7 \\
\hline \multirow{2}{*}{ Stormwater flow } & Volume(ML/year) & 2490 & 2490 & 2490 & 2257 & 2069 & 2477 & 2277 \\
& Peak(ML/day) & 1808 & 1808 & 1808 & 1808 & 1860 & 1810 & 1808 \\
\hline \multirow{3}{*}{ Sewage contaminants } & TN (mg/L) & 59.1 & 78.1 & 74.3 & 59.6 & 59.1 & 74.3 & 62.7 \\
& TP(mg/L) & 15.5 & 20.6 & 19.5 & 15.6 & 15.5 & 19.5 & 16.6 \\
& TSS(mg/L) & 259.3 & 343.7 & 338.6 & 261.7 & 259.3 & 338.6 & 279.2 \\
& BOD(mg/L) & 207.5 & 275.1 & 274.2 & 209.4 & 207.5 & 274.2 & 223.3 \\
& COD(mg/L) & 459.2 & 608.7 & 595.1 & 465.4 & 459.2 & 595.1 & 496.3 \\
\hline \multirow{3}{*}{ Stormwater contaminants } & TN(Kg/year) & 4856 & 4856 & 4856 & 4630 & 4846 & 4856 & 4693 \\
& TP(Kg/year) & 375 & 375 & 375 & 365 & 375 & 375 & 367 \\
& BOD(Kg/year) & 101,349 & 101,349 & 101,349 & 99,876 & 101,250 & 101,347 & 100,568 \\
& COD(Kg/year) & 14,951 & 14,951 & 14,951 & 14,144 & 14,936 & 14,950 & 14,325 \\
& \%,995 & 69,995 & 69,995 & 65,553 & 69,926 & 69,993 & 66,548 \\
\hline Supply Reliability & 99.9 & 96 & 98 & 91 & 99.9 & 99.9 & 95 \\
\hline
\end{tabular}

Table 2. Weight for subcriteria [46].

\begin{tabular}{ccc}
\hline Criteria & Subcriteria & Weight \\
\hline \multirow{2}{*}{ Potable water supply } & Volume & 0.47 \\
& Peak & 0.53 \\
\hline \multirow{2}{*}{ Sewage flow } & Volume & 0.48 \\
& Peak & 0.52 \\
\hline \multirow{2}{*}{ Stormwater flow } & Volume & 0.52 \\
& Peak & 0.48 \\
\hline \multirow{3}{*}{ Sewage contaminants } & TN & 0.21 \\
& TP & 0.21 \\
& TSS & 0.20 \\
& BOD & 0.19 \\
& COD & 0.19 \\
\hline \multirow{3}{*}{ Stormwater contaminants } & TN & 0.21 \\
& TP & 0.20 \\
& TSS & 0.19 \\
& COD & 0.20 \\
& COD & 0.20 \\
\hline
\end{tabular}




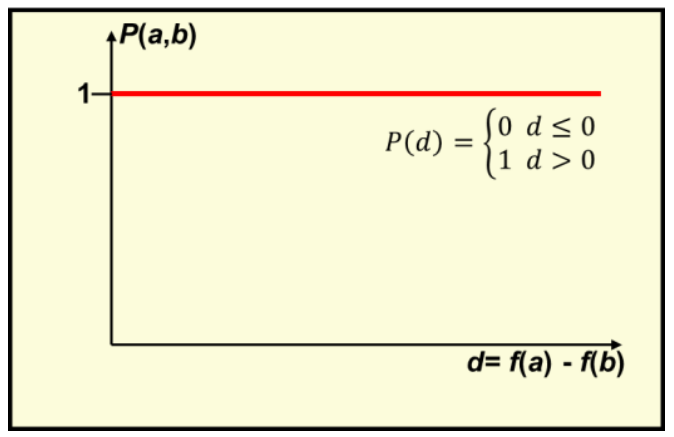

Figure 2. Usual criterion (Type I) preference function.

\section{Results}

This section discusses the MCDA results and their related interpretation. This section first presents the PROMETHEE ranking results. Then, it provides the GAIA analysis for MCDA, followed by the weights sensitivity analysis to ascertain the stability of the ranking results.

\subsection{PROMETHEE Rankings}

The PROMETHEE II rankings of the seven hybrid water supply scenarios with the corresponding values of net flow score $\Phi$ are displayed in Figure 3. Scenario 5 (centralized water supplies combined with stormwater harvesting) is the highest-ranked scenario, with a $\Phi$ score of 0.192 , followed by Scenario 7 (centralized water supplies combined with treated wastewater and rainwater tanks), with a $\Phi$ score of 0.189 . Scenario 2 (centralized water supplies combined with treated wastewater) is the lowest-ranked scenario, with a $\Phi$ score of -0.241 , on the basis of selected criteria.

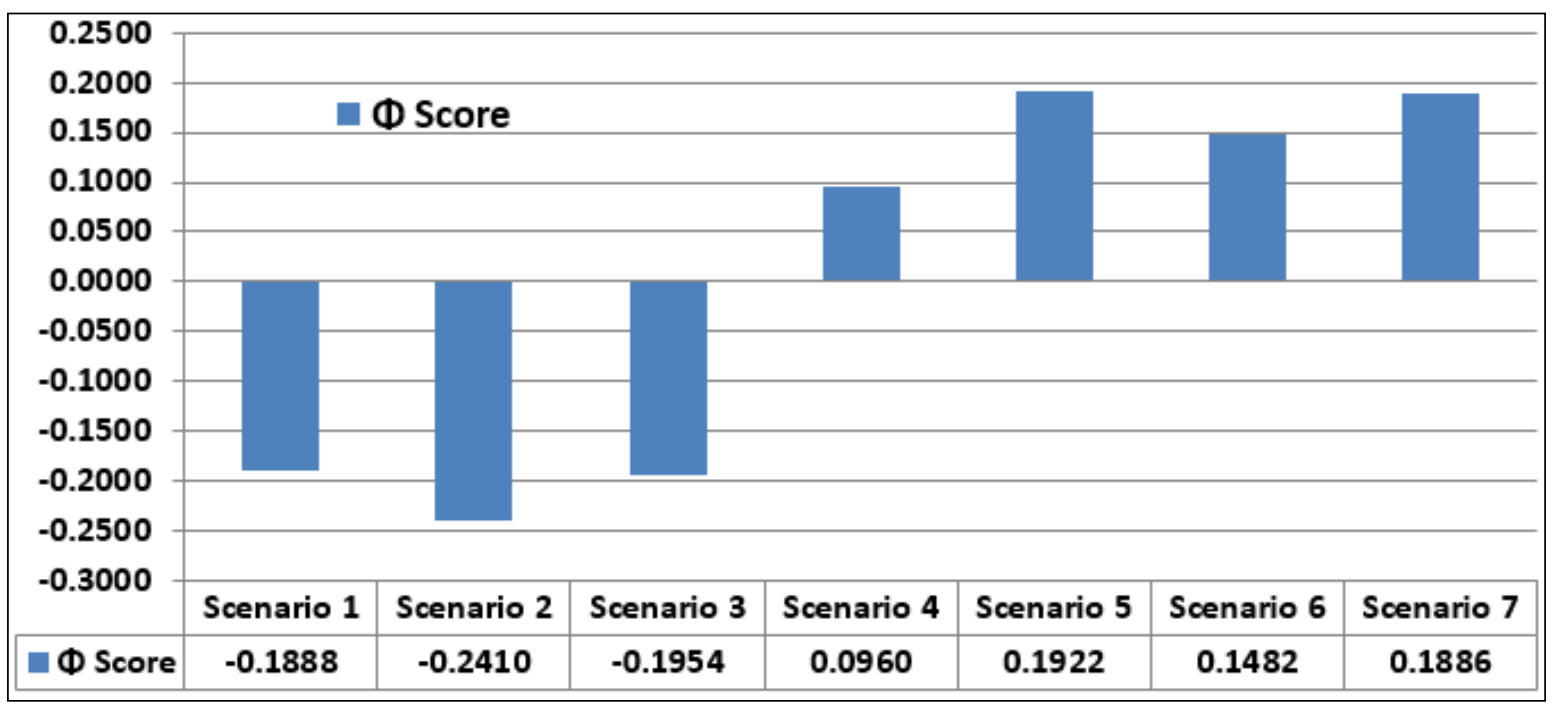

Figure 3. Ranking of hybrid water supply scenarios.

Figure 4 displays the spider web chart for the different hybrid water supply scenarios and allows for the comparison of the strengths and weaknesses of these different scenarios. This web chart shows the comparison of scores between various alternatives for all criteria. Scenario 7 (centralized + treated wastewater + rainwater tanks) provides the best outcome in terms of reduction in potable water supply volume, while Scenario 4 (centralized + stormwater) is strong in reducing the stormwater volume. 


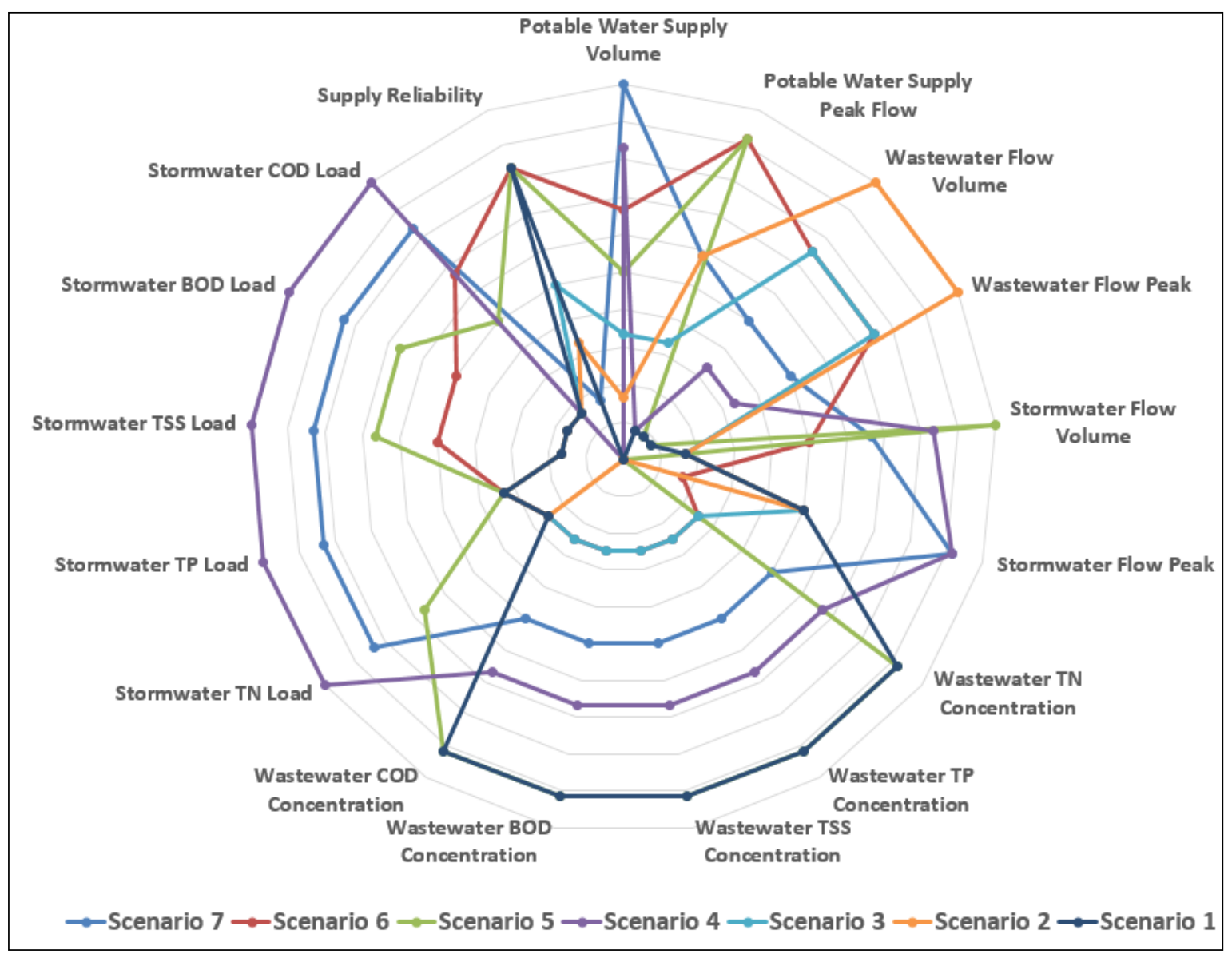

Figure 4. Spider web chart for different hybrid water supply scenarios.

\subsection{GAIA Analysis}

Figure 5 shows the GAIA plane for this decision problem. The criteria are represented by the labelled axes while the scenarios (alternatives) are represented by the points. The GAIA plane in Figure 5 has a value of $84.23 \%$, a percentage that shows that the quality of the two-dimensional representation can be considered good to interpret the results, as a delta value greater than $60 \%$ is considered to be reliable [29]. The value of $84.23 \%$ for this study indicates that the information projected by the plane is sufficient to interpret the PROMETHEE results.

The nonlabelled axis (the red line in Figure 5) is the decision stick that is obtained by projecting the weight vectors onto the GAIA plane. It indicates the current best direction for a compromise solution. Because the direction of the decision stick is in the same direction as the potable water volume, as well as stormwater volume, peak, and contaminants loads, it can be expected that the PROMETHEE II ranked actions to be stronger on those criteria and potentially weaker on criteria such as wastewater concentration and supply reliability of fit-for-purpose water supply.

The decision stick signifies the directions of the best performing scenario based on the criteria weight. If the scenarios are projected on the decision stick, scenario ranking can be obtained. However, it should be noted that the decision stick is a projection of the weight vector on the GAIA plane. Its length is directly related to the angle between the weight vector and the GAIA plane. There can be some distortions in the decision stick results. These distortions are directly proportional to the angle between the weight vector and the GAIA plane. When the decision stick has a shorter length, it is at a larger angle with the GAIA plane, leading to higher distortion. Hence, the representation of the stick can be imprecise, leading to important discrepancies between the PROMETHEE ranking and ranking given by the decision stick in the GAIA plane [37]. For instance, in Figure 5, Scenario 4 appears to be 
the best performing scenario (farthest in the direction of decision axis), although it is the fourth best in PROMETHEE II ranking. According to PROMETHEE II ranking, Scenario 5 is the best decision scenario. Scenario 2 is the worst in the GAIA analysis, as it is located farthest in the opposite direction axis. The PROMETHEE II ranking also shows the same scenario as the worst ranked, which validates the result.

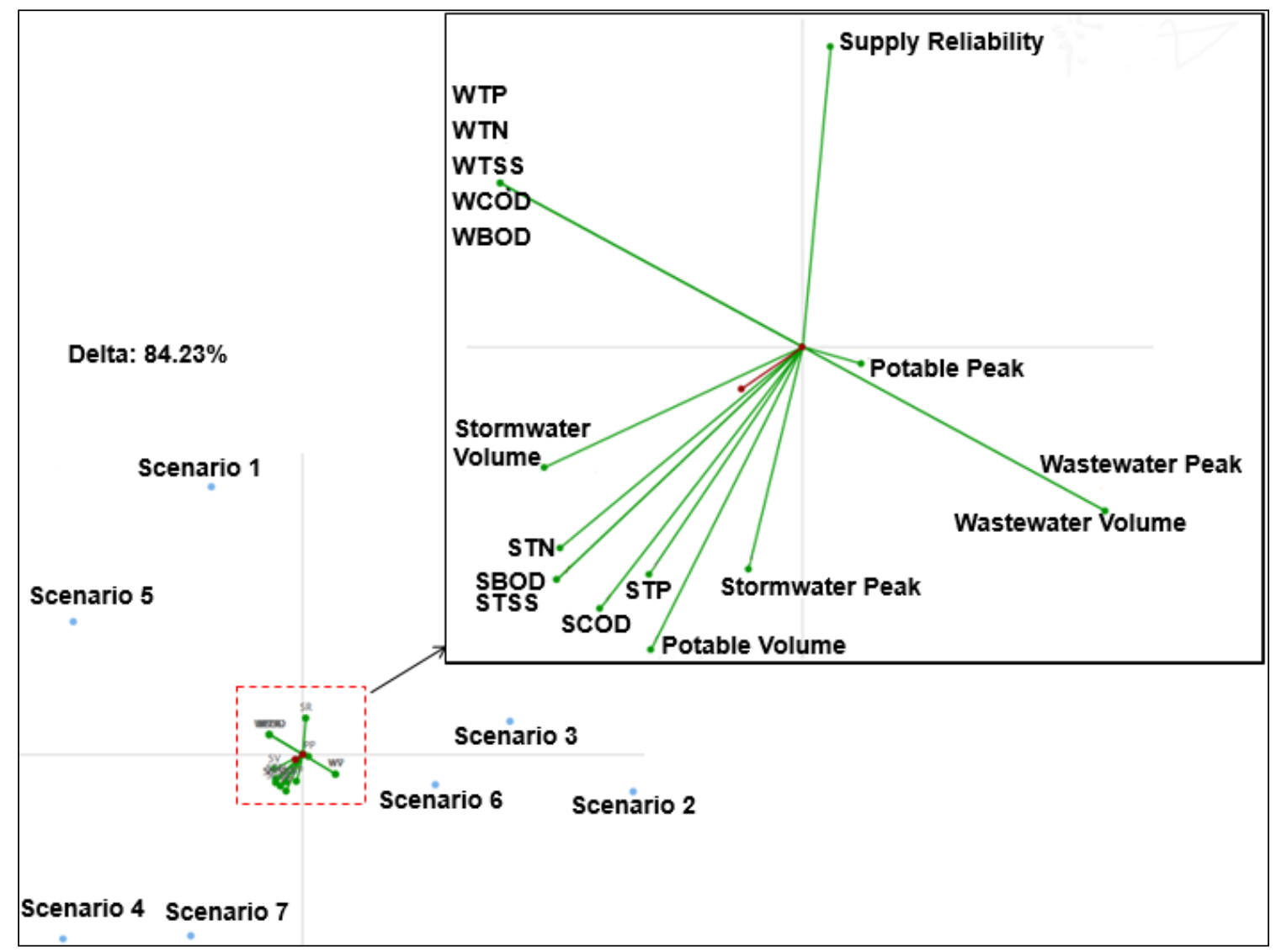

Figure 5. GAIA plane $($ delta $=84.23 \%)$.

It should be noted that the length of the decision stick $(\pi)$ is short on the GAIA plane (red line in Figure 5). Hence, the decision maker should not decide the alternatives based on GAIA plane only because a short $\pi$ indicates a lack of strong decision power [49]. This means that the criteria are strongly conflicting according to the weights and the selection of a good compromise solution is difficult [29]. According to Fernández [50], if the decision stick is long, the decision maker should select the alternatives that are farther in its direction, and if the decision stick is short, the criteria are strongly conflicted and a good compromise solution would be one close to the origin. In the GAIA plane (Figure 5), Scenario 5 is the closest scenario from the origin to the direction of the decision axis, which according to the PROMETHEE ranking, is the best compromise solution.

The GAIA plane also represents the orientation of PMs with respect to the hybrid water supply scenarios. The best alternatives for various preference measures are presented in Table 3.

The criteria having a longer axis (green lines in Figure 5) indicate that they have more strength in differentiating the hybrid water supply scenarios. Preference measures such as wastewater volume, peak and contaminant concentration, supply reliability, and potable water supply volume have a relatively long axis, which indicates that these PMs are more discriminating in differentiating the hybrid water supply scenarios. Conversely, considering the preference of hybrid water supply scenarios, the potable water peak has a relatively shorter length, indicating little differentiating power between the scenarios. 
Table 3. Best alternatives based on various criteria.

\begin{tabular}{|cc|}
\hline Criteria & Best Alternative \\
\hline Wastewater contaminants & Scenario 5 \\
\hline Potable water peak & Scenario 6 \\
\hline Wastewater volume & Scenario 6 \\
\hline Wastewater peak & Scenario 6 \\
\hline Supply reliability & Scenario 1 \\
\hline Potable water volume & Scenario 7 \\
\hline Stormwater peak & Scenario 7 \\
\hline Stormwater volume & Scenario 4 \\
\hline
\end{tabular}

In Figure 5, it can be observed that preference measures-wastewater peak, wastewater volume, and potable water peak - are in the same direction, which indicates a similar preference. Additionally, these PMs have a negative correlation with wastewater contaminants concentration (TP, TN, TSS, BOD, and COD), which is also supported by the scenario analysis results. Scenarios reducing wastewater peak and volume include greywater and wastewater reuse, which ultimately increase the wastewater concentration. These scenarios also reduce peak potable water use, as recycled water is used for toilet and garden irrigation.

Stormwater peak flow, total volume, and contaminant loads, as well as potable water volume, indicate similar preference and are completely opposite to supply reliability of fit-for-purpose water supply. Ideally, the negative correlation of a given pair of PMs indicates conflicting preferences between decision makers on corresponding PMs. For example, scenarios in Figure 5 show that less wastewater volume has high concentrations of wastewater contaminants. However, the comparison between other PMs, such as potable water peak with wastewater contaminant concentration, is impractical and difficult to explain in the hybrid water supply scenarios context, as there is no direct relationship between these two preference measures.

\subsection{Sensitivity Analysis}

Table 4 illustrates the weight sensitivity analysis in terms of weight stability intervals. Weight stability intervals provide the range of PM weights (i.e., maximum and minimum) within which the ranking of alternatives is considered stable. The "Current Weight" column in Table 4 shows the weights obtained from the questionnaire survey for all PMs considered in this study. The "Minimum and Maximum Weight" columns indicate the range of weights which can be assigned to different PMs, such that the ranking of the hybrid water supply scenarios remains unchanged. A larger PM weight stability interval indicates that the PM is less likely to have any large effect on altering the ranking and vice versa.

Potable water supply peak flow, stormwater peak flow, wastewater contaminants (TN, TP, TSS, $\mathrm{BOD}$, and COD) concentration, and supply reliability of fit-for-purpose water have a larger stability interval than other PMs (over 80\%) (Table 4). Stormwater concentration is found to be the most sensitive PM in altering the rankings, as it has the lowest range of stability interval (less than 5\%). Further, potable water supply volume, wastewater flow volume and peak, and stormwater flow volume are found to be sensitive, with a stability interval of less than $10 \%$. 
Table 4. Weight sensitivity for the alternatives.

\begin{tabular}{|ccccc|}
\hline Preference Measures & $\begin{array}{c}\text { Current Weight } \\
(\%)\end{array}$ & $\begin{array}{c}\text { Minimum } \\
\text { Weight (\%) }\end{array}$ & $\begin{array}{c}\text { Maximum } \\
\text { Weight (\%) }\end{array}$ & $\begin{array}{c}\text { Range Difference } \\
(\%)\end{array}$ \\
\hline Potable Water Supply Volume & 9.09 & 0 & 9.42 & 9.42 \\
\hline Potable Water Supply Peak Flow & 7.95 & 7.44 & 100 & 92.56 \\
\hline Wastewater Flow Volume & 8.82 & 0 & 9.23 & 9.23 \\
\hline Wastewater Flow Peak & 8.02 & 0 & 8.43 & 8.43 \\
\hline Stormwater Flow Volume & 8.18 & 0 & 8.36 & 8.36 \\
Stormwater Flow Peak & 7.41 & 6.89 & 100 & 93.11 \\
\hline Wastewater TN Concentration & 3.31 & 2.87 & 100 & 97.13 \\
\hline Wastewater TP Concentration & 3.18 & 2.75 & 100 & 97.25 \\
\hline Wastewater TSS Concentration & 2.99 & 2.55 & 100 & 97.45 \\
\hline Wastewater BOD Concentration & 3.24 & 2.8 & 100 & 97.2 \\
\hline Wastewater COD Concentration & 3.17 & 2.74 & 100 & 97.26 \\
\hline Stormwater TN Load & 3.46 & 0 & 4.53 & 4.53 \\
Stormwater TP Load & 3.47 & 0 & 3.83 & 3.83 \\
\hline Stormwater TSS Load & 3.35 & 0 & 4.42 & 4.42 \\
Stormwater BOD Load & 3.22 & 0 & 4.3 & 4.3 \\
\hline Stormwater COD Load & 3.18 & 0 & 3.72 & 3.72 \\
\hline Supply Reliability & 17.95 & 17.72 & 100 & 82.28 \\
\hline
\end{tabular}

\section{Discussion}

The PROMETHEE ranking conducted in this study shows that Scenario 5 (centralized system along with stormwater harvesting) is the best preferred scenario. At the same time, Scenario 7 (centralized system along with treated wastewater and rainwater tanks) is found to be the second preferred scenario. Benefits associated with stormwater flow volumes make Scenario 5 robust. However, the stormwater volume is stable only within a narrow range of weights, as highlighted via weight sensitivity analysis.

The GAIA analysis provides the decision maker with an additional perspective of the multi-criteria problem. In this analysis, Scenario 5 (centralized water supply system along with stormwater harvesting) is found to be the best and Scenario 2 (centralized water supply system along with treated wastewater) to be the worst. The PROMETHEE ranking also shows the same ranking of these two scenarios, which validates GAIA analysis.

The GAIA analysis also provides the strength of criteria to evaluate different hybrid water supply scenarios. These perspectives are important to explore the structure of the decision problem to better understand the characteristics of different hybrid water supply scenarios. Overall, PROMETHEE ranking along with sensitivity and GAIA analysis demonstrate strong potential to evaluate hybrid water supply scenarios in a multi-objective environment.

This study shows possible trade-offs in various scenarios based on importance or weight of selected criteria. For example, based on this, centralized with treated waste water is found to be the least preferred scenario, but if the increased concentration of wastewater was not considered as important as other criteria, then the outcome could have been different. This illustrates that the prioritization of criteria by decision makers unsurprisingly has an impact on the results. Thus, this adds complexity to defining the best hybrid water supply scenario. The aim of this paper was to evaluate hybrid water supply scenarios in terms of interaction with existing centralized system, and most relevant criteria were selected for ranking. However, further analysis can be conducted with due consideration of other parameters, such as cost of water infrastructures, social factors, and energy usage. Apart from this, a smaller time scale, such as hourly, can be captured to analyze the overall system dynamics of hybrid water supply systems. More qualitative aspects such as social behavior and acceptance, and their impact on the hybrid water supply systems, can be considered in a future study. MCDA criteria weights in the study were mainly based on water professionals. However, community end users' perceptions could make a difference in the weight. Besides, this study does not aim to study in detail the uncertainties involved in various parameters of the model. Further 
research can incorporate uncertainty analysis thoroughly. In addition to this, the aspects of system failure and associated cost as suggested in [51,52] can be a part of the overall business planning of water service providers.

Thus, the proposed framework in a decision-making context would be one part (focusing on the physical aspects of the system) of a more comprehensive framework that would consider such other factors. This study has significant implications for the urban water system decision-making process. Urban water professionals can employ ranking methods as shown in the study to justify the most suitable solution while implementing decentralized water supply options in existing centralized systems. In particular, it is noted that the proposed methodology has considerable potential for evaluating improvements in supply reliability, which is a key aspect of water safety plans as recommended by the World Health Organization [53].

\section{Conclusions}

Multi-criteria decision analysis along with GAIA analysis is presented to identify the preferred hybrid water supply scenario in the Northern Growth Area of Melbourne, Australia. Both of the analyses highlight that all hybrid water supply scenarios perform better than the centralized only scenario. PROMETHEE ranking along with sensitivity and GAIA analysis demonstrate how the methodology can be used for the evaluation of hybrid water supply scenarios in a multi-objective environment.

The following conclusions can be summarized from the study:

- MCDA analysis shows that Scenario 5 (centralized system along with stormwater harvesting) is the most preferred scenario, with Scenario 7 (centralized system along with treated wastewater and rainwater tanks) is the second preference.

- The same analysis shows that Scenario 2 (centralized with treated waste water) is presented as the worst scenario in the study.

- GAIA analysis shows that Scenario 5 (centralized water supply system along with stormwater harvesting) is the best and Scenario 2 (centralized water supply system along with treated wastewater) is the worst

- Thus, MCDA and GAIA analyses provide similar results in terms of scenario ranking

- Potable water supply peak flow, stormwater peak flow, and wastewater contaminant concentration are found to be the most robust criteria in ranking the hybrid water supply scenarios

- Stormwater contaminant load is found to be the unstable criterion in ranking the scenarios.

In a nutshell, this paper highlights various hybrid water supply scenarios which can be further analyzed with additional criteria by diverse stakeholders, including policy makers, water managers, and professionals, to fulfil the objectives of a sustainable water supply system. Also, it will be interesting to analyze and understand whether changing demographics and climate conditions have any effect on the ranking of hybrid water scenarios.

Author Contributions: All authors were involved in designing and discussing the study. M.S. performed the modelling, analysis and led the writing of this paper. M.A., H.M., A.S. and M.M. supervised the research. All authors discussed the results and implications and commented on the manuscripts at all the stages.

Acknowledgments: Authors are grateful to Bureau of Meteorology (BoM), Melbourne Water and Yarra Valley Water (YVW) for their kind assistance in the study, particularly providing the data and sharing their valuable experiences in the field. Also, we would like to thank Francis Pamminger from YVW, Melbourne, Biju George from BoM, Melbourne, and Prasad Inamdar from Department of Industries, New South Wales for their valuable suggestions during the study.

Conflicts of Interest: The authors declare no conflict of interest. 


\section{References}

1. Tsoukalas, I.K.; Makropoulos, C.K.; Michas, S.N. Identification of potential sewer mining locations: A monte-carlo based approach. Water Sci. Technol. 2017, 76, 3351-3357. [CrossRef] [PubMed]

2. Cook, S.; Sharma, A.K.; Gurung, T.R. Evaluation of alternative water sources for commercial buildings: A case study in Brisbane, Australia. Resour. Conserv. Recycl. 2014, 89, 86-93. [CrossRef]

3. Ashbolt, S.C.; Perera, B.J.C. Multicriteria analysis to select an optimal operating option for a water grid. Water Resour. Plan. Manag. 2017, 143, 05017005. [CrossRef]

4. Sharma, A.K.; Pezzaniti, D.; Myers, B.; Cook, S.; Tjandraatmadja, G.; Chacko, P.; Chavoshi, S.; Kemp, D.; Leonard, R.; Koth, B. Water sensitive urban design: An investigation of current systems, implementation drivers, community perceptions and potential to supplement urban water services. Water 2016, 8, 272. [CrossRef]

5. Sapkota, M.; Arora, M.; Malano, H.; George, B.; Nawarathna, B.; Sharma, A.; Moglia, M. Development of a framework to evaluate the hybrid water supply systems. In Proceedings of the 20th International Congress on Modelling and Simulation, Adelaide, Australia, 1-6 December 2013; pp. 2387-2393.

6. Sapkota, M.; Arora, M.; Malano, H.; Moglia, M.; Sharma, A.; George, B.; Pamminger, F. An overview of hybrid water supply systems in the context of urban water management: Challenges and opportunities. Water 2015, 7, 153-174. [CrossRef]

7. Marleni, N.; Gray, S.; Sharma, A.; Burn, S.; Muttil, N. Impact of water management practice scenarios on wastewater flow and contaminant concentration. J. Environ. Manag. 2015, 151, 461-471. [CrossRef] [PubMed]

8. Marlow, D.R.; Moglia, M.; Cook, S.; Beale, D.J. Towards sustainable urban water management: A critical reassessment. Water Res. 2013, 47, 7150-7161. [CrossRef] [PubMed]

9. Sapkota, M.; Arora, M.; Malano, H.; Moglia, M.; Sharma, A.; George, B.; Pamminger, F. An integrated framework for assessment of hybrid water supply systems. Water 2016, 8, 4. [CrossRef]

10. Sharma, A.; Burn, S.; Gardner, T.; Gregory, A. Role of decentralised systems in the transition of urban water systems. Water Sci. Technol. 2010, 10, 577-583. [CrossRef]

11. Weber, B.; Cornel, P.; Wagner, M. Semi-centralised supply and treatment systems for (fast growing) urban areas. Water Sci. Technol. 2007, 55, 349-356. [CrossRef] [PubMed]

12. Poustie, M.S.; Deletic, A.; Brown, R.R.; Wong, T.; de Haana, F.J.; Skinner, R. Sustainable urban water futures in developing countries: The centralised, decentralised or hybrid dilemma. Urban Water J. 2015, 12, 543-558. [CrossRef]

13. Sitzenfrei, R.; Zischg, J.; Sitzmann, M.; Bach, P.M. Impact of hybrid water supply on the centralised water system. Water 2017, 9, 855. [CrossRef]

14. Sharma, A.; Grant, A.L.; Grant, T.; Pamminger, F.; Opray, L. Environmental and economic assessment of urban water services for a greenfield development. Environ. Eng. Sci. 2009, 26, 921-934. [CrossRef]

15. Sapkota, M.; Arora, M.; Malano, H.; Moglia, M.; Sharma, A.; Pamminger, F. Understanding the impact of decentralised water supply scenarios on wastewater and stormwater flows. Resour. Conserv. Recycl. 2018, 130, 82-94. [CrossRef]

16. Abrishamchi, A.; Ebrahimian, A.; Tajrishi, M.; Mariño, M.A. Case study: Application of multicriteria decision making to urban water supply. J. Water Resour. Plan. Manag. 2005, 131, 326-335. [CrossRef]

17. Al-Shemmeri, T.; Al-Kloub, B.; Pearman, A. Model choice in multicriteria decision aid. Eur. J. Oper. Res. 1997, 97, 550-560. [CrossRef]

18. Hajkowicz, S.; Collins, K. A review of multiple criteria analysis for water resource planning and management. Water Resour. Manag. 2007, 21, 1553-1566. [CrossRef]

19. Moglia, M.; Sharma, A.K.; Maheepala, S. Multi-criteria decision assessments using subjective logic: Methodology and the case of urban water strategies. J. Hydrol. 2012, 452-453, 180-189. [CrossRef]

20. Vincke, P. Multicriteria Decision-Aid; Wiley: West Sussex, UK, 1992.

21. Ganoulis, J. Evaluating alternative strategies for wastewater recycling and reuse in the mediterranean area. Water Sci. Technol. Water Supply 2003, 3, 11-19.

22. Braune, I.; Pinkwart, A.; Reeg, M. Application of multi-criteria analysis for the evaluation of sustainable energy systems-A review of recent literature. In Proceedings of the 5th Dubrovnic Conference on Sustainable Development of Energy, Water and Environment Systems, Dubrovnik, Croatia, 30 September-3 October 2009. 
23. Al-Kloub, B.; Al-Shemmeri, T.; Pearman, A. Theory and methodology-The role of weights in multi-criteria decision aid, and the ranking of water projects in jordan. Eur. J. Oper. Res. 1997, 99, 278-288. [CrossRef]

24. Butler, D.; Jowitt, P.; Ashley, R.; Blackwood, D.; Davies, J.; Oltean-Dumbrava, C.; McIlkenny, G.; Foxon, T.; Gilmour, D.; Smith, H.; et al. Sward: Decision support processes for the UK water industry. Manag. Environ. Qual. An Int. J. 2003, 14, 444-459. [CrossRef]

25. Van Moeffaert, D. Multi Criteria Decision Aid in Sustainable Urban Water Management. Master's Thesis, Deptartment of Industrial Ecology, Royal Institute of Technology (KTH), Stockholm, Sweden, 2003.

26. Brans, J.P.; Vincke, P.; Mareschal, B. How to select and how to rank projects: The promethee method. Eu. J. Oper. Res. 1986, 24, 228-238. [CrossRef]

27. Brans, J.-P.; Mareschal, B. The PROMCALC \& GAIA decision support system for multicriteria decision aid. Decis. Support Syst. 1994, 12, 297-310.

28. Behzadian, M.; Kazemzadeh, R.B.; Albadvi, A.; Aghdasi, M. Promethee: A comprehensive literature review on methodologies and applications. Eur. J. Oper. Res. 2010, 200, 198-215. [CrossRef]

29. Brans, J.P.; Mareschal, B. Promethee methods. In Multiple Criteria Decision Analysis: State of the Art Surveys; Figueira, J., Greco, S., Eds.; Springer Science + Business Media, Inc.: New York, NY, USA, 2005; pp. 163-195.

30. De Smet, Y.; Lidouh, K. An introduction to multicriteria decision aid: The PROMETHEE and GAIA methods. In Business Intelligence; Aufaure, M.-A., Zimányi, E., Eds.; Springer: Berlin/Heidelberg, Germany, 2013; pp. 150-176.

31. Hayez, Q.; De Smet, Y.; Bonney, J. D-Sight: A New Decision Support System to Address Multi-Criteria Problems; Technical Report number TR/SMG/2011-004; Universite Libre de Bruxelles: Brussels, Belgium, 2011.

32. Mustajoki, J.; Marttunen, M. Comparison of Multi-Criteria Decision Analytical Software; Report on IMPERA Project; Finish Environmental Institute: Helsinki, Finland, 2013.

33. Mutikanga, H.E.; Sharma, S.K.; Vairavamoorthy, K. Multi-criteria decision analysis: A strategic planning tool for water loss management. Water Resour. Manag. 2011, 25, 3947-3969. [CrossRef]

34. Zardari, N.H.; Yusop, Z.; Shirazi, S.M.; Roslan, N.A.B. Prioritization of farmlands in a multicriteria irrigation water allocation: PROMETHEE and GAIA applications. Trans. ASABE 2015, 58, 73-82.

35. Peng, Y.; Zhang, Y.; Kou, G.; Shi, Y. A multicriteria decision making approach for estimating the number of clusters in a data set. PLoS ONE 2012, 7, e41713. [CrossRef] [PubMed]

36. Hayez, Q.; De Smet, Y.; Bonney, J. D-sight: A new decision making software to address multi-criteria problems. Int. J. Decis. Support Syst. Technol. IJDSST 2012, 4, 1-23. [CrossRef]

37. Hayez, Q.; Mareschal, B.; De Smet, Y. New GAIA visualization methods. In Proceedings of the IEEE 13th International Conference on Information Visualisation, Barcelona, Spain, 15-17 July 2009; pp. 247-251.

38. Nemery, P.; Mareschal, B.; Ishizaka, A. Unification of problem formulation with promethee: Keynote paper. In Proceedings of the 52th Operational Research Society Conference, London, UK, 7-9 September 2010; Volume 1.

39. Kodikara, P.N. Multi-Objective Optimal Operation of Urban Water Supply Systems. Ph.D. Thesis, Victoria University, Victoria, Australia, 2008.

40. Mareschal, B.; De Smet, Y. Visual promethee: Developments of the PROMETHEE \& GAIA multicriteria decision aid methods. In Proceedings of the IEEE International Conference on Industrial Engineering and Engineering Management (IEEM 2009), Hong Kong, China, 8-11 December 2009; pp. 1646-1649.

41. Mousseau, V. Eliciting information concerning the relative importance of criteria. In Advances in Multicriteria Analysis; Pardalos, P.M., Siskos, Y., Zopounidis, C., Eds.; Springer: New York, NY, USA, 1995; pp. $17-43$.

42. Stewart, T.J. Dealing with uncertainties in mcda. In Multiple Criteria Decision Analysis: State of the Art Surveys; Springer: New York, NY, USA, 2005; pp. 445-466.

43. Inamdar, P.M. Selection and Evaluation of Potential Stormwater Harvesting Sites in Urban Areas. Ph.D. Thesis, Victoria University, Victoria, Australia, 2014.

44. Mitchell, V.G.; Diaper, C. Simulating the urban water and contaminant cycle. Environ. Model. Softw. 2006, 21, 129-134. [CrossRef]

45. Mitchell, V.G.; Diaper, C.; Gray, S.R.; Rahilly, M.; Technolgy, C.M.A.I. Uvq: Modelling the movement of water and contaminants through the total urban water cycle. In Proceedings of the 28th International Hydrology and Water Resources Symposium, Wollongong, Australia, 10-14 November 2003; p. 8. 
46. Sapkota, M.; Arora, M.; Malano, H. Multi-criteria decision analysis for hybrid water supply systems. In Proceedings of the 22nd International Congress on Modelling and Simulation (MODSIM), Hobart, Australia, 3-8 December 2017; pp. 1794-1800.

47. Gliem, J.A.; Gliem, R.R. Calculating, interpreting, and reporting cronbach's alpha reliability coefficient for likert-type scales. In Proceedings of the Midwest Research-to-Practice Conference in Adult, Continuing, and Community Education, Columbus, OH, USA, 8-10 October 2003; pp. 82-88.

48. Brans, J.P.; Vincke, P. A preference ranking organisation method: (The promethee method for multiple criteria decision-making). Manag. Sci. 1985, 31, 647-656. [CrossRef]

49. Ranjan, R.; Chatterjee, P.; Chakraborty, S. Performance evaluation of Indian states in tourism using an integrated PROMETHEE-GAIA approach. Opsearch 2015, 53, 63-84. [CrossRef]

50. Fernández, N.G. The Management of Missing Values in PROMETHEE Methods. Master's Thesis, Universitat Politècnica de Catalunya, Barcelona, Spain, 2013.

51. Pietrucha-Urbanik, K. Assessing the costs of losses incurred as a result of failure. In Dependability Engineering and Complex Systems; Zamojski, W., Mazurkiewicz, J., Sugier, J., Walkowiak, T., Kacprzyk, J., Eds.; Springer: Cham, Switzerland, 2016; Volume 470, pp. 355-362.

52. Pietrucha-Urbanik, K.; Żelazko, A. Approaches to assess water distribution failure. Period. Polytech. Civ. Eng. 2017, 61, 632. [CrossRef]

53. Tchorzewska-Cieslak, B. Risk management in water safety plans. Ochr. Srod. 2009, 31, 57-60.

(C) 2018 by the authors. Licensee MDPI, Basel, Switzerland. This article is an open access article distributed under the terms and conditions of the Creative Commons Attribution (CC BY) license (http:/ / creativecommons.org/licenses/by/4.0/). 